\title{
Reflective discussions in teacher training: A comparison between online and offline discussions of course literature in a class of pre-service teachers
}

\author{
Ann-Britt Enochsson ${ }^{1}$ (D)
}

Received: 16 December 2016 / Accepted: 29 March 2017 /Published online: 19 April 2017

(C) The Author(s) 2017. This article is an open access publication

\begin{abstract}
This paper compares outcomes of student teachers' use of oral classroom and written online forum discussions of course literature, with the aim of examining how each mode facilitates reflective practice. Data were collected from a class of 11 participating student teachers. Oral discussions were video-recorded and written online discussions were saved as Word files. Clinchy's levels of knowing were used to determine the depth of the reflections and qualitative analyses inspired by Harasim were carried out as a complement. Findings indicate that on a group level the performance according to the levels of reflective thinking was the same. Both modes have advantages and drawbacks, but it is clear that there should be a variety of modes to provide individual student teachers with better possibilities of developing their reflections. Further explorations of the interaction between modal preference and modal performance, as well as the implications for online peer collaboration, are discussed.
\end{abstract}

Keywords Computer-mediated communication $\cdot$ Media in education $\cdot$ Improving classroom teaching $\cdot$ Pedagogical issues $\cdot$ Teaching/learning strategies

\section{Introduction}

An important element in the professional development of student teachers is their progression towards becoming reflective practitioners - reflecting on and in practice (Schön 1987). This can be evidenced in both oral and written forms of assessment. These two evaluative processes - oral feedback (for example in discussions) and written reflections (for example in reflective journals or assignments) - are seen as

Ann-Britt Enochsson

ann-britt.enochsson@kau.se

1 Department of Educational Studies, Karlstad University, 65188 Karlstad, Sweden 
different modes; some students who do not perform well in writing might be better in oral discussions, and vice-versa.

A key difference in terms of how these two modes are 'performed' is that while oral discussion is generally interactional, written assignments are typically completed in solitude. When students are given a written assignment, they do not get the same feedback as in a discussion, and some may even struggle with the lone nature of the written form. Nevertheless, this latter form, for practical reasons, was often the most convenient way to arrange for students who had been absent at an oral discussion to complete the course requirements at our university. Against this background, when contemporary web tools for written discussions online began to become easily accessible to all students, we decided to further develop the literature discussions in our courses by letting the students try out written forms of reflective discussion seminars in which they were encouraged to take an active part and write follow-up comments to each other's comments.

In course evaluations the students mentioned the positive sides of discussing literature online. To most of them this was a new way of reflecting on research literature in relation to their future practice, but they viewed the experience as positive, since participation seemed more equal. Some of them expressed that this mode suited them very well indeed.

It is one thing to do something the students like or feel comfortable with and another thing to organize good learning situations. We wanted to provide training in reflective thinking and wanted to know if written online discussions could fulfil the same role as oral discussions in that respect. We also wanted to know if there were important aspects that could differ. According to the literature we found, the area seemed to be quite unexplored, so we decided to study the outcomes of what we did more thoroughly.

\subsection{Aim and research questions}

The aim of this article is to compare outcomes of student teachers' use of oral classroom and written online forum discussions for reflections on course literature. In comparing the two modes of discussion, the following questions were to be studied:

- Do the students develop their reflections on the same academic levels in both modes at group level?

- Do the students develop their reflections on the same academic levels in both modes at an individual level?

- Is there any difference in the structure of the modes?

Not so many comparisons have been done in the existing literature, so we designed an explorative small-scale study to find aspects that can be analyzed in depth later. The third research question relates to aspects that can cause any differences.

\section{Literature review}

All students referred to in this overview are higher education, like the students in the present study. Most of them are from North America, but some are from Scandinavia 
and Australia, and there is one example each from Israel and Taiwan. Although our article reports on a study involving student teachers, there are few existing examples from teacher education. This is can reflect what is found by Enochsson and Buskqvist (2011), namely that digital assessment, and thereby also online assessment, is less commonly used in teacher education than in other higher education.

One benefit of online reflection is the possibility to transcend the limits of time and space (Zieger and Pulichino, 2004). Highlighting its versatility and accessibility is a commonly used as an argument in support of online reflection (Tsang 2011). This argument can also be used for economic reasons and can explain why decision-makers are easily convinced of the advantages of online education. Several researchers claim, furthermore, that group discussions online promote students' critical thinking (Jones and Ryan 2014; Saadé et al. 2012; Garrison et al. 2001; Wu and Hiltz 2004), but it is important that the discussions are well structured and preferably led by a moderator (Yang 2008; Garrison and Cleveland-Innes 2005; Dysthe 2001), since reflection does not come automatically (Pedro 2012).

Some researchers have studied the role of a moderator explicitly, and in a course this is usually the teacher. Pedro (2012) let student teachers practice reflective thinking while the teacher interfered. The conclusion of this project was that by using certain techniques introduced by the teacher, the students deepened their comprehension of the studied subject and enhanced their meta-cognitive awareness of teaching. Jones and Ryan (2014) found that students are often left alone to make connections between the theory in teacher education and practice in classrooms. Therefore they compared the role played by structured and unstructured online peer discussions in improving practice in rural areas. Groups of pre-service teachers had discussions during their practice period with the aim of deepening their reflection and critical thinking. The researchers found that the discussions did not reach the expected depth, in spite of the presence of moderators. The researchers still argued that a structured online discussion can promote reflective thinking in teacher education.

Others point at students' own activities in a course and that they engage in each other's contributions and not just make their own posts. In online discussions in health care education, students in the focus group were interviewed about their experiences (Nilsen and Lundvoll Nilsen 2013), and stated that the technology helped promote reflection, as it gave them time to think and it was possible to go back and see what others had written.

To measure student participation Wu and Hiltz (2004) developed a statistical tool, which was connected to assessment data (ibid.). Other researchers are critical of using quantitative measures for assessment (e.g. Dysthe 2001; Garrison and Cleveland-Innes 2005). Malmberg and Svingby (2004) used social networking analysis to study what students learned in asynchronous discussions. Certain factors were valued as important when students were being assessed and it was shown that the number of contributions was strongly related to the students' grades. This means the more text, the higher the grades, regardless of content. It is therefore important to be aware of how student engagement is defined.

Wise et al. (2013), see also Wise et al. 2012, following 95 students, identified three distinct patterns of behaviour in students' online community communication. They called it 'online listening behaviour'. These categories differed in depth, breadth, temporal contiguity and reflectivity in reading as well as writing. The researchers 
concluded that for learning, it is important that students do not just lurk, but also actively engage. Although there were distinct differences between students' reflective behaviour, grades did not differ according to the students' online listening behaviour. The researchers found this surprising, but the finding is in line with Malmberg and Svingby's (2004) result (see above).

As described above, there are factors affecting how students engage and develop or show their critical reflection in online forums, e.g. structure, presence of a moderator, and guidance. Garrison et al. (2000) use a model with three elements essential for an online discussion to become a community of inquiry and so be used for learning purposes. The researchers built their ideas on John Dewey's and Matthew Lipman's theories, putting forth three elements that are essential for an online discussion to become a community of inquiry: cognitive presence, social presence and teaching presence, which each has a set of indicators. Indicators for cognitive presence include: a triggering event, recognizing the problem, exploration, information exchange, integration, connecting ideas and creating solutions. The indicators correspond to different phases of critical educational inquiry. Examples of indicators for social presence include: emotional expression, emoticons, autobiographical narratives, acknowledging others, being encouraging, encouraging collaboration, helping, and supporting. Examples of teaching presence indicators include: instructional management, structuring content, setting discussion topics, establishing discussion groups, building understanding, sharing personal meaning/values, expressing agreement, seeking consensus, directing instruction, focusing and pacing discussion, answering questions, diagnosing misconceptions and summarizing learning outcomes or issues.

In an Israeli context using quantitative content analysis techniques in 50 forums with almost 5000 students participating, Gorsky et al. (2010) studied the presence of Garrison et al.'s three key elements and found that the presence of these elements was higher in science forums than in the humanities, but that the ratio of the three elements was constant between the subjects. Social presence was the most prevalent, more than the other two elements together. Swan et al. (2008) found through factor analysis that the model promotes deep learning. Using a certain model does not insure learning; Dysthe (2001) shows that the way the assignment is formulated is crucial for the dialogue and thereby for what the students can learn. An aspect found to be important for engagement in forums is well-being (Pendry and Salvatore 2015), which is not always easy to build into the course design.

\subsection{Comparing modes}

Most research has been done on the online setting only, and few have tried to compare the two modes. Stodel et al. (2006) asked what students missed from online learning and their conclusion was that new learners online have to be coached and that it takes time for them to learn. The expectations of the online community have to be articulated and managed and as a teacher it is important to understand all learners. To students, social presence seems to be important for the outcome (Akyol et al. 2009). This is what students said when the researchers compared online and blended courses. The students in this study preferred the blended mode where they could also meet face-to-face.

A group of teachers in teacher education in Sweden had four different groups when discussing course literature (Thörne et al. 2017). The same students did not attend 
online and offline forums. After the discussions, the researchers asked the students in a questionnaire what they thought about the seminar, if they thought the discussions were good and what they had learned from them, if they could show their knowledge during the seminar and if they thought everybody was active in the discussions. There was a big difference in how the online and offline students experienced learning. Significantly more offline students answered 'definitely' to the question about learning.

The idea for the present study came from earlier studies where face-to-face interviews with children were compared with online interviews from different aspects (Enochsson 2007a, 2011), showing clear gender and age differences in the way they expressed themselves. The children in these studies were between 10 and 16 years old. The boys expressed themselves more substantially orally, while the girls did the same in writing. The older the children, the larger the differences, but there were also clear differences between gender and age when the interview questions had a more personal character, which was interpreted as the mode in which you felt comfortable being important when you really have something to say. In contrast to earlier studies, this study focuses on how individuals perform in different modes.

\section{Theoretical framework}

There are strong reasons for researching this area according to Tsang (2011):

Despite of a common consensus that critical reflection is relevant, the concept of critical reflection itself is contentious. Evidence from the literature indicates that critical reflection is ill-defined and open to interpretation. (p. 59)

One way of determining the depth of reflection is to use theories about critical thinking. In the 1950s, Perry (1970) developed his nine-phase theory in three levels, but he was criticized for only using male informants. Clinchy $(1990,1996)$ pointed to women's different voice (an expression borrowed from Gilligan 1995) regarding critical thinking, which she preferred to call knowing/knowledge. According to Clinchy, Perry (1970) described a type of knowing that is mostly represented among males, which Clinchy called separate knowing because it manifests itself in distancing oneself from and questioning another person's perspectives. Clinchy did similar studies with women and found another way of expressing critical thinking, which was more common among females. She called this connected knowing. A person dominated by connected knowing tries foremost to understand the other person's perspective. According to Clinchy, it is important to develop both separate and connected knowing.

These types of knowing or critical thinking can also be seen at different levels. The least developed level is unreflective knowledge. The person can reproduce something. The next level means that the person is able to understand what is learnt and relate it to his or her experience. On the third level, a person can also value the knowledge, question and compare it to other phenomena. This is complex thinking. In this article, I have chosen to call the three different levels of thinking (A) unreflective, (B) related and (C) complex, which are concepts developed in earlier studies (Enochsson 2001a, b, 2007b). 
As indicated in the introduction and earlier research, critical thinking does not develop in the same way in solitude as in a discussion. As an alternative to the lone work of writing a paper, the written, online forum is regarded as an alternative to get feedback from others. The theoretical base is thereby a sociocultural view, where learning is seen as a process of enculturation into a community of practice (Lave \& Wenger, 1991). It is assumed that student teachers in their last semesters share an understanding of what constitutes an oral discussion on course literature and in this respect belong to a community of practice, since this is a common way to work. Harasim (2012) builds on this theoretical perspective in her model for online collaborative learning. She identifies three intellectual phases in knowledge building: idea generating, idea organizing and intellectual convergence. Group members contribute with their understanding and ideas, organize them and together build understanding and knowledge (Harasim, 2012).

\section{Material and methods}

\subsection{Setting}

The students in this study were all training to become secondary teachers in Sweden. They had different subject combinations. Secondary teachers' education is offered at master's level, and the selected group comprized student teachers in their last year. On average, this group of students is aged around 28 in Sweden, and this can assumed to have been the case in this group too, even if we did not ask for their ages. Since these students were in their final year, they would have been familiar with what would be assessed in this kind of seminar, during which course literature was being discussed. The course has three grade levels: P (Pass), PwD (Pass with Distinction) and F (Fail). In general, students pass as long as they participate in the discussions and show that they understand the main message of the discussed course literature. In oral discussions it can sometimes be difficult for the teacher to register to what extent individual students participate actively and in practice, physical presence can be enough to pass. To receive the higher grade, PwD, the students have to show a deeper understanding of the content. This can mean for example going beyond what is taken for granted and showing an independent standpoint, or a critical view, which they communicate in a way that others can understand.

Students who are absent from the seminar for one reason or another are often asked to write a short summary of the text(s) and their reflections. In earlier courses, absent students could also be asked to read their fellow students' notes and develop reflections based on them. The forms of examinations are set in the course syllabi and cannot be changed without a decision by the faculty board. The main reason for this is to ensure quality but also to provide a variation of assessments. Exchanging a discussion for a written paper without feedback from fellow students turns the examination into something different, often without further reflection, but is a convenient way of organizing absentees without having to set up a new seminar with similar discussions.

By developing the oral discussions into written online forums, we could still follow the course syllabus, which prescribed a discussion, but we did not know how the mode and the medium would change the examination conditions prerequisites for the 
examination. The aim of this paper was thus to delve deeper into this subject. Would it be possible in a similar way to develop reflections on literature in an online written forum? Even if computers had not been used this way in the courses, Swedish students normally have their own computers at home (Findahl and Davidsson, 2016). Should this not be the case, the university provides computers for student use. Being a full-time student at this specific university does not mean coming to campus every day. Students keep in touch with the teacher via the course platform, and between students applications like Facebook and Skype are frequently used. The selected class did not differ from other groups in this respect. They were used to contacting each other from home in between classes at the university.

\subsection{Data collection}

Data were collected from a course with 11 participating student teachers. Normally this group is larger and we aimed at studying a larger group, several students were absent for different reasons. It was important to be able to study the same group online and offline. This limited the students we could ask to participate. Their task for these sessions was to discuss course literature based on the questions: What was interesting for you in this text? What would you like to problematize? What did you learn that might be useful in your future profession? The subject of the course was how to use ICT in pedagogical environments, which made it easy to let the students try an online forum when discussing one of the course books. They were all quite experienced, and although not all of them were frequent users, the technology itself was not a problem. Other discussions on similar, but not the same, course literature took place in traditional classroom settings and were video-recorded, first in two small groups where the student teachers discussed independently of the teacher and later in a bigger group discussion led by the teacher.

Normally, there are two teachers for this course, but during this study, one of us abstained for ethical reasons, namely so students would not feel they were obliged to participate in order to get higher grades. The remaining teacher was not involved in either the information or the consent process and was not allowed to know which students participated until after the grades were set. There was an agreement that the video recordings would not show students who did not wish to participate, and this was not a problem. All students in the course gave their consent individually with the explanation from one of them that they themselves would soon ask for other respondents' consent when working with their minor theses. Four students chose not to be visible in the video recordings, but participated orally.

\subsection{Analyses}

The oral discussions were transcribed from the video recordings and the transcriptions were analysed, as were the texts from the online forums, which the students themselves had written. The analyses had two aspects. The first was to analyse the content of what is expressed in relation to the assessment criteria in the course. This was related to the first two research questions. Sentences from the transcripts were categorized according to the levels of critical thinking, as described above - unreflective, related and complex (Clinchy 1990, 1996; Enochsson 2001a, b, 2007b). Using this analysis, it was possible 
to determine the general level of critical thinking in the discussions and also which students developed their comments further towards a more advanced level of critical thinking.

The second aspect related to background aspects and involved analysing the structure of the discussions, using a more ethnographical and holistic approach, searching for the three phases in Harasim's (2012) model for online collaborative learning (see above). In this analysis, the recorded videos were watched several times. The analysis was explorative and we noted how much individuals talked or wrote and how they expressed themselves. A special focus was on idea generating, idea organizing and intellectual convergence. Patterns were identified from these notes. We based the analyses on a design taken from Ehn and Löfgren (1982), who used five techniques common in ethnographical research, but which are also useful in text analyses: (1) question what seems to be obvious, (2) think in contrasts, (3) dramatize - turn things upside-down, (4) look for recurrent features and finally (5) challenge the interpretation. These techniques also help the researcher to be more true to the respondents' perspective.

\subsubsection{Examples of analyses}

The phrases in the transcriptions were analysed according to the three levels of critical thinking or knowledge described above. Messages that did not add anything to the discussion about the content of the book (for example all the comments when one of the students' mobile phones rang) were not considered; only comments related to the literature were included. Comments which merely said, 'I think this was good', were considered as being on the (A) unreflective level, if the student did not expand on the way in which it was good.

Coding and grouping the comments like this, it was easy to conclude that most of what was said could be categorized as a lower level of knowledge, but there were also many other statements. When the students related the content of the book directly to their practice, this was categorized as level (B) related. One of the chapters in one of the books discussed copyright and one student showed that she understood what it said, but made the remark that she has seen that some teachers did not follow all the rules and regulations (Michelle). The (C) complex level was demonstrated when the students questioned the content or compared the theories. An example of this was when a student in one of the discussions questioned the meaning of a concept, age-adapted play, arguing that the concept was used in too narrow a sense and explaining what she meant (Emmy).

\section{Results}

The results are organized in two sections following the first two research questions. The results related to the third question are integrated into these two parts, since it should be seen as background. We first presented the group discussions that took place in small offline and online groups, then the class discussion led by the teacher. This is followed by an example of a male student who was the most obvious case of a single person showing his reflective thinking differently in the two settings. 
Counting words and phrases showed that some students easily took up 'verbal space' in the room while others did not; the space was more evenly distributed online. A simple statistical analysis showed that different people used the verbal space differently depending on mode and also size of group.

\subsection{Offline group discussions}

All discussions started out from the three questions above. The class was divided into two discussion groups, which I call Group A and Group B in the below.

\subsubsection{Group a offline. Participants: Emmy, Michelle, Laura, Maud}

In this group, the discussion was totally dominated by Emmy. Regardless of counting words, phrases or time, she used more verbal space than the other three taken together. On one occasion one of the others tried to say something before Emmy was through, who began to speak louder and faster until the other one gave up so she could continue. In the class discussion, the teacher asked them how the discussions had gone in their respective groups. Emmy answered for the group by saying that they all contributed to the discussion and listened to each other. According to Harasim's (2012) categories, Emmy had the role of idea generator as well idea organizer in her group. She was also the one who decided on her group's contribution.

In general, analysing using Clinchy's levels of knowledge, this discussion stayed in the middle. The students mainly evaluated ideas from the literature and drew parallels to their fieldwork or future professional life. Only two of the students, Emmy and Michelle, demonstrated a higher level of knowledge while the two others mainly talked on the lowest level, quoting the literature or saying that they liked or disliked it without developing their views further.

\subsubsection{Group B offline. Participants: Anne, Adam, Hailey, Leah, Matthew}

Leah began by saying she did not think that the book took up anything new, just pedagogical theories they had studied earlier throughout their education. The title indicated that the book should have been about disabilities and ICT, but she could not see that. What she did get out of the reading was her own associations, and she thought that was interesting, but the book did not help her learn more. The others were in strong agreement, and they strongly agreed several times after Leah had been talking. Matthew for instance said, 'I had a feeling of fragmentation'. Anne said it was all rather obvious and Hailey said she missed the depth that comes from discussing pedagogical consequences. Leah was the idea generator, but unlike Group A offline (above), the group organized their ideas together. They had a long, critical discussion about the literature, questioning the content and the way it is presented. Suddenly the conversation took this turn:

Leah: We've lost the concept, I think.

Adam: This discussion isn't very tight. 
Leah: Carol [the teacher] isn't here to steer the discussion, so we can go off on tangents.

In general, the contributions in this group were on a higher level than in the other group. Anne, who was neither a big talker during class discussions nor wrote very much, was one of the dominating students here. She was comfortable with the subject since she had worked with disabled children, the topic of the literature. An interesting point, however, is that the same literature was discussed in the class seminar, where she was much quieter. Her way of discussing gave the impression that she thought she knew how things were or should be. She questioned the literature several times because it did not say anything about certain theoretical perspectives on disabilities, even if she admitted that she had not read all of it. She also questioned the content of the course, saying there had not been enough training in using digital equipment. Even though she questioned certain aspects, her reasoning was not always well developed.

\subsection{Online discussions}

The discussions online had a similar structure as the offline discussions, except that fewer words were used online. The similarities included students introducing the subjects to discuss, defining problem areas, following up on each other's reflections, etc. The online seminars were divided into several threads. Students were free to start new threads as long as they fulfilled the given criteria, which were that they had to start out from the same questions as the oral seminars and had to write several times, as well as relate to the others. The two groups did not discuss exactly the same literature and were kept separate in different forums for organizational reasons. The groups were thus the same as those in the group seminars (with the difference that each group had a student who was absent at the time of the oral seminars).

\subsubsection{Group a online. Julia joined the online discussions in group a}

This group started out with social small talk, checking with each other that everything was okay, which was the same pattern as offline. The students apparently had an agreement to sit by the computer at the same time and to discuss in real time. Emmy was less dominant online and the balance between the group members was more equal. Online, it was not only Emmy who came up with all the ideas.

I turned out later in the threads that Michelle and Julia were not present and the three remaining students discussed why. They also discussed the literature and decided after a while to check in later to see if the others showed up. In fact there were three members of the group absent, but one of them had disappeared in administration and was not added to the course platform (or the course) until later. This student started a discussion by himself after the others had finished, calling for the others but without any success.

The first three students wrote some small talk before leaving the forum and quite soon after that one of the absent students showed up. The second showed up the next day.

The five female students had a discussion together, but in general it did not develop to a high level of knowledge. Laura, who did not develop her thoughts on a higher level in the oral discussions, did do so here. Maud touched this level when she wrote that 
teachers in schools and after school clubs often had different perspectives on learning and teaching thus might be a problem when trying to work together around the children. She also presented a specific solution to this problem.

\subsubsection{Group B online. John joined the online discussions in group B.}

This group spent no time on small talk and chose to work asynchronically, keeping the discussion on a subject level and writing only what was required. Their level of critical thinking was about the same as when they discussed offline, meaning it was more developed than in Group A. Adam, who never finished a sentence orally, brought up several developed comments online. Below, he is described as an example of a student who totally changed his behaviour in the two modes. The online mode changed the balance of idea generation and all group members contributed to the ideas and subjects discussed.

\subsection{Class discussion}

The discussion was led by the teacher, who gave the floor to each student, one at a time. This means that all of them contributed to idea generation, while the teacher organized the ideas and summarized their shared understanding. Only the second question automatically led to a deeper analysis and this was of course a reason for the distribution in categories. Group B had its most developed discussion in the small group offline where they questioned the literature and discussed its merits. They seemed to be limited by a teacher moderating comments in a big offline discussion.

Although one of the questions involved scrutinizing the literature, there were still three students who did not reach a higher level of knowledge. Two of them, Laura and Maud, did not discuss at this level in their online group either, whereas the third one, Anne, dominated in this sense in her group, which was not the same group as Laura and Maud's. On the other hand, one of the students speaking the least, Hilary, said nothing that classified on the received knowledge level. The few things she did say were more developed.

The students developed their thoughts less when the teacher was present - not talking less, but not presenting the profound, developed reflections they put forth when they were on their own.

\subsection{Summary of group discussions}

No difference can be seen regarding the first research question whether the students develop their reflections on equal levels in both modes at group level. The participating students used fewer words online when writing than offline when talking, but produced similar content. Results indicate that some students seem to dominate the discussions offline. This does not happen in the online forums. In class, the teacher worked as a moderator, and this led to less developed thoughts than when the students were in smaller groups.

\subsection{Adam - An interesting case}

Offline: Adam was a very quiet student offline. He gave the impression, however, of doing very well. After the teacher-led discussion, both the teacher and I agreed that he 
had been doing well. When analysing the video recordings, it was obvious that he had only been saying 'uh-huh' or uttering short, one-word phrases or incomplete sentences, like (quotes translated from Swedish):

The personal cases?

I found it a little bit obvious myself.

Yes, I thought he was a little bit...

The reason we both had the impression that he contributed to the discussion was probably that he was following the discussion very well, which he also showed with his body language. His 'uh-huh's' were always in the 'right' place, and this 'seduced' us into believing that he was talking more than he actually did. Similar things happened in the discussion in the small group. Adam never finished his sentences offline.

Online: In the online discussion, Adam became more visible. Another student initially referred to a couple of computer games, CIV and Backpacker, and Adam answered:

CIV is really possible to use in history and geography classes. In the sense that the game offers an 'authentic' aspect when you have to choose what things to develop at what time and with which kind of resources, etc. The problem with using games in education is, as we said earlier, how to assess this?

Adam also initiated threads:

I got a feeling, not only reading this book but also the other two, a feeling that they are incredibly positive to learning through computers and by computers.

I think there are social processes in learning, and school is an agent of socialization for the younger pupils. How can you interact with computers and their learning processes and include the social thing and our assignment to educate and nurture?

He finished his thoughts and sentences and his contribution to the discussions in the written conversations was significant. He was the student who showed the most obvious difference in the two modes, and our interpretation was that this mode suited him very well. Nevertheless he wrote in the open course evaluation (there was also an anonymous part of the evaluation):

In spite of the technology this was enormously disturbing and it was hard to get control of anything, but at least it was an experience. 
This was a common sentiment and another student made a short comment, a sort of 'off topic' comment where she said that, despite her 'big love of computers', having seminars in this way was really tiresome, when you could not see the others. She preferred a 'traditional seminar'.

When Adam was talking in the group without the teacher, the average length of his contributions was less than seven words (the average for his group was 16); in the bigger group, where the teacher sometimes directed questions to him, it was 16 words (the average for the group was 23). Online the average length of his contributions was 71 words (the average of the group was 58). His greater visibility online was good in relation to the assessment from the teacher's point of view, but Adam was not totally comfortable.

Adam was not the only student who changed depending on mode. Several of the others did the same. Some became more visible online and others less visible online. A few took up the same amount of space online as offline.

\subsection{Summary on the individual case}

On an individual level, a difference could be seen in the extent to which several students developed their reflections and Adam is the most obvious example of this. Adam did not seem to be quick enough to talk offline when the others were talking as well, but there were also examples to the contrary. It seems the difference is due to personal preferences.

\section{Discussion}

The aim of this article is to compare outcomes of student teachers' use of oral classroom discussions with written online forum discussions for reflections on course literature. Before we started the project, we thought there might be a difference in how students structured the discussions and also a difference in content. In this study, some students dominated the offline discussions in both groups even if in different ways, and this can be a reason why some individuals did not to contribute as much to the discussion as they might have done with other collaborators. There were also similarities. The reason for the latter may be that the students were used to the kind of examination where course literature was discussed. The idea they had of the online examinations, which were, like offline examinations, called 'course literature seminars', may have led them into this kind of structure. They also received the same kind of instructions from the teacher. Those who started off with small talk did so online as well as offline. There was also a difference in the number of words used, which was not surprising (cf. Enochsson, 2011).

The depth of the discussions according to the theoretical framework developed in earlier studies (Enochsson 2001a, b, 2007b) from theories on critical thinking (see above) did not differ between the modes either, when looking at the group level. The differences became obvious however when looking at the individual level. Some individuals changed behaviour when changing modes. Some developed their thoughts more and others less when shifting to the online mode. 
There was a noticeable difference when the students were left alone in the room compared to the teacher-led discussion. The influence of the teacher was a bit surprising since it was an examination where the students were supposed to show what they had learnt. The teacher's influence is an important lesson here, but falls outside the scope of this article.

Earlier research show that participants in online discussions have a greater opportunity to develop their thoughts than offline (Garrison et al. 2001; Jones and Ryan 2014; $\mathrm{Wu}$ and Hiltz 2004), that training is needed and that the discussion needs to be well structured (Garrison and Cleveland-Innes 2005; Dysthe 2001). In the present study no training was provided. As a consequence, not all of the students succeeded in developing their thoughts as well as they might have done with training, even if there was a structure set by the teacher and the teacher interfered when she found it necessary. Some students may have trained in other forums or just liked writing better than talking. Worth noticing is that the balance of who was generating ideas changed between the modes.

In Garrison et al. (2000) model it is claimed that teaching, cognitive presence and social presence are important. Only one of the groups spent time on small talk, but the students probably knew each other well since it was a campus-based course and they were in their last semester. The assumption is that small talk was not needed in the discussions, since they may have carried it out already, perhaps the day before. The teacher was present to a certain degree in deciding the structure and she interfered if needed. The cognitive presence was the same as offline. The students discussed, answered, supported, etc.

In another Swedish study, students engaged in online discussions claimed that they preferred offline discussions (Thörne et al. 2017). In that study, however, the same students did not try both offline and online discussions. Moreover, evaluation was done by asking the students themselves, i.e. self-estimation, and not by analysing the content. In the present study, the students said they were somewhat frustrated, but nevertheless they performed well. The self-estimated experience is not always an adequate measure.

Enochsson (2007a, 2011) found that young girls expressed more in writing than orally; for boys it was the opposite. From a perspective of gender being constructed and not biologically determined, this can also be seen as individuals having different preferences regardless of gender. In the present study, Adam, the interesting example, is a male student, but he seems to be the shy type. He only talks when he is given a turn, otherwise he just agrees with the others. In the written forum, where it was mandatory to write something, he did what was required.

\subsection{Limitations}

In the light of other studies and despite this being a small study, the results are reasonable. To strengthen the results, the same study could be done in a larger number of groups and classes. It would also be beneficial to study the long-term effects of the discussions by analysing the students' term papers.

When studying people there are many factors that affect behaviour. The online and offline discussions did not take place the same day, for instance. They were held during the same week, but many things can happen which can affect a student's concentration. 
The course literature differed as well, even if the subject and level of difficulty were similar, according to the teachers. But using the same literature in another class or another semester means that society is different and students are different and comparisons become complicated.

\subsection{Implications and significance}

The results of this study show that the discussions had similarities at a group level and that the differences were at the individual level. The explanation according to the theoretical framework is that individuals are different and need different ways of developing and that the social context matters.

What does this mean for teaching practice? One conclusion is that not all students, even if they have chosen to become teachers, are comfortable talking in groups. Multimodality is thus a way of increasing everyone's chances of making themselves heard and also of developing their thoughts with the aim of becoming reflective practitioners. Not everyone, for a variety of reasons, has optimal opportunities to develop their thoughts if, for example, they are a bit shy or uncomfortable when talking in a group.

It is important to note that there is not only a distinction between oral and written modes, but also between different kinds of writing. The forums we used in combination with the instructions encouraged the students to discuss in a similar way as in the physical room. One of the groups even chose to sit at the same time although it was not a medium that required synchronicity. Synchronous and asynchronous online communications serve different purposes. Synchronous instant messaging has its benefits when geographical distance is a hindrance for communication; the asynchronous forums work better for groups with different working hours, for example.

A discussion does not always lead to fully developed reasoning, regardless of whether it is online or offline. Writing an essay requires previously developed thoughts. When feedback is given days - or weeks - after, the student has probably moved forward, thinking of other courses and other subjects.

Some students prefer writing, others talking and yet others prefer other expressions. To help all student teachers in their progression towards becoming reflective practitioners and to develop as professionally as possible, digital media with their multimodality may be a good help. With the speed of technological development, there may yet be many other possibilities to come.

\section{Conclusion}

Although some conclusions can be drawn from this study, it generated more questions than answers: How do we design a learning environment that encourages all students to share their thoughts and experiences so they can become reflective practitioners? Is it possible to combine several modes? Nonetheless the following can be concluded:

- Individuals have different preferences regarding how to express their thoughts

- The digital landscape offers many possibilities in this respect 
- Those who educate teachers should use a variety of different modes to offer student teachers better opportunities to develop their reflections

- Training is needed since the way the media is mastered affects the message

Traditions have a strong impact on how we teach and as instructors of teachers, we need to think out of the box and not always do things as we have always done them. We have clearly seen here when scrutinizing our own lectures that things are not always what we think at first glance. Letting students use many different modes of expression allows them to develop their thoughts. The digital world offers many possibilities to help student teachers become reflective practitioners.

Open Access This article is distributed under the terms of the Creative Commons Attribution 4.0 International License (http://creativecommons.org/licenses/by/4.0/), which permits unrestricted use, distribution, and reproduction in any medium, provided you give appropriate credit to the original author(s) and the source, provide a link to the Creative Commons license, and indicate if changes were made.

\section{References}

Akyol, Z., Garrison, R., \& Ozden, Y. (2009). Online and blended communities of inquiry: Exploring the developmental and perceptional differences. International Review of Research in Open and Distance Learning, 10(6). doi:10.19173/irrodl.v10i6.765.

Clinchy, B. M. V. (1990). Issues of gender in teaching and learning. Journal on Excellence in College Teaching, 1, 52-67.

Clinchy, B. M. V. (1996). Connected and separate knowing. In N. R. Goldberger, J. M. Tarule, B. M. Clinchy, \& M. F. Belenky (Eds.), Knowledge, difference and power: Essays inspired by Women's ways of knowing (pp. 205-247). New York: Basic Books.

Dysthe, O. (2001). The asynchronous webmediated discussion as a learning genre. Conference proceeding, Genres and discourses in education - Work and Life, Oslo, May 13-16.

Ehn, B., \& Löfgren, O. (1982). Kulturanalys. Lund: Liber.

Enochsson, A. (2001a). Children choosing web pages. The New Review of Information Behaviour Research: Studies of Information Seeking in Context, 2(2), 151-165.

Enochsson, A. (2001b). Meningen med webben: En studie om Internetsökning utifrån erfarenheter $i$ en fjärdeklass [The Use of the Web: Fourth Grader's Experiences of Doing Internet Searches] (Karlstad University Studies 2001:7). Doctoral dissertation in Pedagogy, Karlstad: Karlstad University.

Enochsson, A. (2007a). Gendered interviewing?: A comparison of online and face-to-face interviews. Paper presented at ECER 2007, Ghent 19-21.

Enochsson, A. (2007b). Sant eller falskt på nätet: Tonåringar resonerar om kritisk granskning [True or false on the net]. In U. Palmenfelt (Ed.), Børn og Kultur - I samfunn? (Vol. 2). Bergen: BIN-Norden.

Enochsson, A., \& Buskqvist, U. (2011). ICT, teacher education and assessment: What is assessed and how is it done? Paper presented as part of a symposium at the 39th NERA Congress in Jyväskylä, Mar 10-12.

Enochsson, A. (2011). Who benefits from synchronous online interviews?: A comparison of face-to-face and synchronous online interviews with children. Procedia: Social and Behavioral Sciences, 28(2011), 1522.

Findahl, O., \& Davidsson, P. (2016). Svenskarna och Internet [the swedes and the Internet]. Stockholm: Internetstiftelsen.

Garrison, D. R., \& Cleveland-Innes, M. (2005). Facilitating cognitive presence in online learning: Interaction is not enough. The American Journal of Distance Education, 19(3), 133-148.

Garrison, D. R., Anderson, T., \& Archer, W. (2000). Critical inquiry in a text-based environment: Computer conferencing in higher education. The Internet and Higher Education, 2(2-3), 1-19.

Garrison, D. R., Anderson, T., \& Archer, W. (2001). Critical thinking, cognitive presence, and computer conferencing in distance education. American Journal of Distance Education, 15(1), 7-23.

Gorsky, P., Caspi, A., Antonovsky, A., Blau, I., \& Mansur, A. (2010). The relationship between academic discipline and dialogic behavior in open university course forums. International Review of Research in Open and Distance Learning, 11(2). 
Harasim, L. (2012). Learning theory and online technologies. New York: Routledge.

Jones, M., \& Ryan, J. (2014). Learning in the practicum: Engaging pre-service teachers in reflective practice in the online space. Asia-Pacific Journal of Teacher Education, 42(2), 132-146. doi:10.1080/1359866 X.2014.892058.

Lave, J., \& Wenger, E. (1991). Situated learning: Legitimate peripheral participation. New York: Cambridge University Press.

Malmberg, C., \& Svingby, G. (2004). Students' dialogues and contributions in education for sustainable development. In P. Wickenberg, H. Axelsson, L. Fritzén, G. Helldén, \& J. Öhman (Eds.), Learning to change our world?: Swedish research on education \& sustainable development. Lund: Studentlitteratur.

Nilsen, R. \& Lundvoll Nilsen, L. (2013). Interprofessional participation and reflection in a digital network. Seminar.net 9(1). http://seminar.net/volume-9-issue-1-2013/205-interprofessional-participation-andreflection-in-a-digital-network. Accessed 16 Dec 2016.

Pedro, J. (2012). Reflecting on literacy practices. Journal of Digital Learning in Teacher Education, 29(2), $39-47$.

Pendry, L. F., \& Salvatore, J. (2015). Individual and social benefits of online discussion forums. Computers in Human Behavior, 50(2015), 211-220.

Perry Jr., W. G. (1970). Intellectual and ethical development in the college years. New York: Holt, Rinehart and Winston.

Saadé, R. G., Morin, D., Thomas, J., \& D.E. (2012). Critical thinking in E-learning environments. Computers in Human Behavior, 28, 1608-1617. doi:10.1016/j.chb.2012.03.025.

Schön, D. A. (1987). Educating the reflective practitioner: Toward a new design for teaching and learning in the professions. San Francisco: Jossey-Bass.

Stodel, E., Thompson, T., \& MacDonald, C. (2006). Learners' perspectives on what is missing from online learning: Interpretations through the community of inquiry framework. International Review of Research in Open and Distance Learning, 7(3). doi:10.19173/irrodl.v7i3.325.

Swan, K., Richardson, J., Ice, P., Garrison, R., Cleveland-Innes, M., \& Arbaugh, J. (2008). Validating a measurement tool of presence in online communities of inquiry. E-Mentor, 2(24). http://www.e-mentor. edu.pl/artykul/index/numer/24/id/543. Accessed 16 Dec 2016.

Thörne, K., Flognman, J., \& Jonsson, G. (2017). En forskningscirkel om blended learning och digital examination: Ett lärarlags process mot ökat samarbete, medvetenhet och utveckling. Karlstad: Karlstad University (in press).

Tsang, A. (2011). Online reflective group discussion: Connecting first year undergraduate students with their third year peers. Journal of Scholarship of Teaching and Learning, 11(3), 58-74.

Wise, A., Perera, N., Hsiao, Y.-T., Speer, J., \& Marbouti, F. (2012). Microanalytic case studies of individual participation patterns in an asynchronous online discussion in an undergraduate blended course. The Internet and Higher Education, 15(2012), 108-117. doi:10.1016/j.iheduc.2011.11.007.

Wise, A., Speer, J., Marbouti, F., \& Hsiao, Y.-T. (2013). Broadening the notion of participation in online discussions: Examining patterns in learners' online listening behaviors. Instructional Science, 41(2), 323343. doi:10.1007/s11251-012-9230-9.

Wu, D., \& Hiltz, R. (2004). Predicting learning from asynchronous online discussions. Journal of Asynchronous Learning Networks, 8(2), 139-152.

Yang, C. Y. (2008). A catalyst for teaching critical thinking in a large university class in Taiwan: Asynchronous online discussions with the facilitation of teaching assistants. Educational Technology Research and Development, 56, 241-264.

Zieger, L., \& Pulichino, J. (2004). Establishing a community of learners: A case study of a university graduate orientation program for online learners. Journal of Interactive Online Learning, 2(4), 1-13. 